\title{
Reliability of Estimating Stochastic Lung Tissue Heterogeneity from Pulmonary Impedance Spectra: A Forward-Inverse Modeling Study
}

\author{
David W. Kaczka, ${ }^{1,2}$ Christopher B. Massa, ${ }^{2}$ and Brett A. Simon ${ }^{1,3}$
}

${ }^{1}$ Department of Anesthesiology and Critical Care Medicine, The Johns Hopkins University, Baltimore, MD, USA; ${ }^{2}$ Department of Biomedical Engineering, The Johns Hopkins University, Baltimore, MD, USA; and ${ }^{3}$ Department of Medicine, The Johns Hopkins University, Baltimore, MD, USA

(Published online 26 June 2007)

\section{Erratum to: Annals of Biomedical Engineering} DOI: 10.1007/s10439-007-9339-1

Due to a typesetting error, Eq. (6) was displayed incorrectly. It should read:

$$
\hat{Z}_{\mathrm{L}}(\omega)=R+j \omega I+\left(\int_{H_{\min }}^{H_{\max }} \frac{P(H) \omega^{\alpha}}{(\eta-j) H} d H\right)^{-1}
$$

The model fits to the data using Topology $\mathrm{C}$ were obtained using the above equation, and none of the results or discussion presented in the article are changed.
In addition, the line descriptors for the graphs in Fig. 4 were mislabeled. The correct legend for Fig. 4 should read:

Simulations of lung resistance $\left(R_{\mathrm{L}}\right)$, reactance $\left(X_{\mathrm{L}}\right)$, and elastance $\left(E_{\mathrm{L}}\right)$ spectra from 0.07 to $8.9 \mathrm{~Hz}$ for canine morphometric model under healthy, emphysematous, moderately injured, and severely injured conditions. Data are shown for hyperbolic (solid lines), uniform (dotted lines), and linear (dashed lines) tissue distribution functions.

Address correspondence to David W. Kaczka, Department of Anesthesiology and Critical Care Medicine, The Johns Hopkins University, Baltimore, MD, USA. Electronic mail: dkaczka1@ jhmi.edu

The online version of the original article can be found under doi: 10.1007/s10439-007-9339-1. 